\title{
Séverine Bridoux-Michel, Le Corbusier \& Iannis Xenakis : un dialogue architecture/musique
}

\author{
Nathalie Boulouch
}

1 De l'Expo 58, Bruxelles a conservé l'iconique Atomium. Détruit en 1959, le Pavillon Philips reste une architecture tout aussi emblématique de cette première Exposition universelle d'après-guerre. Imaginé par Le Corbusier à la demande de la Société Philips qui souhaite alors faire la démonstration de ses savoir-faire les plus innovants dans le domaine de l'électronique appliquée, ce bâtiment constitue un exemple remarquable de collaboration auquel ce livre est consacré. Collaboration entre Le Corbusier et Xenakis, collaboration entre les arts. Outre de revenir sur la thématique des rapports entre architecture et musique, l'auteure (architecte de formation) s'attache à la relation intime que Le Corbusier a entretenue avec la musique, puis à celle de Xenakis avec l'architecture, avant de développer une longue étude détaillée du Pavillon, de la genèse en 1956 à la destruction. C'est avec la construction de ce Pavillon que Iannis Xenakis, qui travaille de 1947 à 1959 pour l'Atelier Le Corbusier de la rue de Sèvres, se voit offrir l'opportunité de faire converger ses deux compétences d'ingénieur-architecte et de compositeur à un moment où il commence à être reconnu pour ses compositions musicales avant-gardistes. On découvre comment il impose ses exigences techniques et formelles nourries par ses recherches entreprises pour son œuvre musicale; développant une méthode qui deviendra ensuite sa signature. Le Corbusier lui confie par ailleurs la composition d'un interlude sonore de deux minutes, Concret PH, qui «servait de mise en route du public dans le cadre du spectacle " (Xenakis, cité p. 142). $\mathrm{Au}$ sein de sa structure à voiles minces de béton de forme paraboloïde conçue selon des principes constructifs innovants, le Pavillon Philips a en effet offert aux visiteurs l'expérience d'un environnement où architecture, projection d'images en noir et blanc, jeux de lumière colorée et musique électronique spatialisée d'Edgar Varèse proposaient - durant huit minutes - une forme contemporaine de synthèse des arts: le Poème électronique. Porté par une mise en page graphique originale, cet ouvrage de belle facture est enrichi par un corpus d'illustrations extraites des fonds d'archives consultés 
(Fondation Le Corbusier, Famille Xenakis, Société Philips). Si l'analyse de ce dispositifspectacle audiovisuel et multimédia est bien approfondie du point de vue architectural et musical, on regrettera toutefois que celle des images projetées reste plus limitée. En ce sens, on ne peut que souscrire à une problématique essentielle soulevée par l'auteure : comment étudier des œuvres lorsque le lieu dont elles dépendaient, en tant qu'environnement, a été détruit? Aujourd'hui, les compositions de Varèse et de Xenakis sont le « seul contenu préservé de ce projet éphémère à l'enveloppe matérielle effacée. » (p. 145) 